\title{
Active seed sowing can overcome constraints to passive restoration of a critically endangered vegetation type
}

\author{
Stuart A. Hall ${ }^{\mathrm{a}, \mathrm{b}}$, Patricia M. Holmes ${ }^{\mathrm{a}, \mathrm{b}}$, Mirijam Gaertner ${ }^{\mathrm{b}, \mathrm{c}}$, Karen J. Esler ${ }^{\mathrm{a}, \mathrm{b}, *}$ \\ ${ }^{a}$ Department of Conservation Ecology and Entomology and Centre for Invasion Biology, Stellenbosch University, Private Bag X1, Matieland 7602, South Africa \\ ${ }^{\mathrm{b}}$ Centre for Invasion Biology, Department of Botany and Zoology, Stellenbosch University, South Africa \\ ${ }^{\mathrm{c}}$ Nürtingen-Geislingen University of Applied Sciences (HFWU), Nürtingen, Germany
}

\section{A R T I C L E I N F O}

\section{Article History:}

Received 7 April 2020

Revised 15 December 2020

Accepted 22 December 2020

Available online xxx

Edited by SJ Siebert

\section{Keywords:}

Fynbos

Passive restoration

Habitat conservation

Active restoration

Biological invasions

Threatened plants

\begin{abstract}
A B S T R A C T
Invasive alien plants negatively impact ecosystems, but recovery of native vegetation may fail following standard methods of alien species removal alone. Alternative management actions may thus be required. Cape Flats Sand Fynbos is a critically endangered vegetation type in the Cape Floristic Region of South Africa which is threatened by Acacia saligna invasion, but standard clearing methods have failed to restore native vegetation structure. A restoration study was performed comparing passive treatments i.e. clearing without burning (stack-block) versus clearing and burning (burn-block), as well as active intervention by sowing seeds of native species, either initially after burning or a year later, in which seeds were either not pre-treated or pretreated with smoke and heat exposure before sowing. After two years all treatments resulted in different recovery trajectories, although none resembled the reference condition. Clearing without burning facilitated recovery in less degraded areas with higher initial native shrub cover, but otherwise resulted in limited vegetation recovery. Limited recovery facilitated secondary invasion by herbaceous weeds. Active seed sowing resulted in the highest recovery of native shrub cover and diversity. These findings suggest that passive restoration is constrained by seed limitation, due to the lack of recovery of vegetation components under passive clearing treatment. Active sowing was able to partially overcome this constraint through improved recovery of total shrub cover. However, non-sprouting shrub cover was higher while resprouting shrubs and species of Restionaceae were lower compared to the reference condition. Pre-treatment of seeds before sowing improved establishment of some species. Active treatment involving sowing pre-treated seeds after clearing and burning therefore resulted in best fynbos recovery compared to either of the passive treatments tested. A decision tree has been developed based on these findings in order to guide best protocol for managers.
\end{abstract}

(C) 2020 Published by Elsevier B.V. on behalf of SAAB.

\section{Introduction}

Invasive alien plants are currently a major environmental problem on a global scale (Richardson and Rejmanek 2011) through negative impacts on diversity and ecosystem function (Levine et al., 2003). Counteracting these effects, including preventing introductions, eradicating or controlling invasive species (Wilson et al., 2011), and follow-up control, will likely be necessary for decades (Pretorius et al., 2008). Impacts of invasive species are predicted to further increase around the world (Walther et al., 2009). Plant invasions are particularly problematic in Mediterranean-type ecosystems, which constitute global biodiversity hotspots. Effects have been studied in regions including Portugal (Marchante et al., 2003), California (D'Antonio et al., 2007) and Western Australia (Fisher et al., 2009), as

\footnotetext{
* Corresponding author.

E-mail address: kje@sun.ac.za (K.J. Esler).
}

well as South Africa (Van Wilgen et al. 1998) where the Working for Water Programme was initiated to deal with invasive species.

Fynbos vegetation is a highly diverse sclerophyllous shrubland confined to the Mediterranean climate region in the southwest of South Africa, where many areas are invaded by alien tree species, particularly Australian acacias (Le Maitre et al. 2011). Fire is necessary to stimulate germination of most fynbos species due to fire-related germination cues such as smoke (Brown 1993) and heat (Hall et al., 2016), as has been found for other Mediterranean regions such as Californian chaparral (Keeley 1987) and Australian kwongan (Tieu et al., 2001). Invasive alien species including Acacia saligna (Labill.) Wendl. (Port Jackson willow) are stimulated to germinate by fire (Jeffery et al., 1988), but this facilitates rapid reduction of acacia soil seed banks which would otherwise persist for decades (Holmes et al., 1987). However, increased rate of biomass accumulation by alien vegetation relative to fynbos results in fires of higher severity and increased frequency, which can negatively impact on fynbos recovery (Holmes et al., 2000). 
Lowland vegetation types in the Cape region of South Africa are highly threatened, in part by degradation due to invasive alien plants including Acacia saligna (Rebelo et al., 2006). If cleared and restored, invaded habitats possess high conservation value. Following less severe invasion, native vegetation will recover after clearing alone (Mostert et al., 2017). Vegetation recovery will require fire where native cover is depleted, but a long duration of invasion may deplete native soil seed banks (Le Maitre et al. 2011). In such cases active seed sowing is required to reintroduce lost vegetation components (Holmes et al., 2020).

Invaded mountain fynbos may have a persistent native soil seed bank (Holmes and Cowling 1997b). In lowland fynbos however, seed banks of longer-lifespan species have lower persistence (Holmes 2002) and native seed banks become depleted with time after invasion. Serotinous Proteaceae, which includes the majority of overstorey fynbos species, do not have a soil seed bank, so once they disappear from invaded fynbos sites they will not reappear after alien clearing alone (Holmes and Cowling 1997b; Mostert et al., 2017). Obligate resprouting species persist for a limited time under invasion, after which they may be hard to reintroduce since they have small seed banks (Holmes and Richardson 1999) and do not readily produce seedlings (Marais et al., 2014). Resprouting shrubs are an important vegetation component since they can provide cover more rapidly after fire than seedlings (Rutherford et al., 2011), and the loss of this component has important implications for ecosystem function. Seed dispersal distance is limited in fynbos since most species are dispersed by ants, ballistically or passively (Holmes and Cowling 1997a). Limited dispersal distance has been found to present a restoration barrier in Australian kwongan (Standish et al., 2007) and Californian grasslands (Seabloom et al., 2003). Species diversity does not recover in these vegetation communities following disturbance, suggesting that a biotic threshold may have been crossed (Suding et al., 2004; Gaertner et al., 2012a). Limited dispersal ability of many fynbos species (Slingsby and Bond 1983) therefore suggests that fynbos vegetation degraded by invasion is constrained by seed-limitation and may also have crossed a biotic threshold where ecologically important species have disappeared from the ecosystem.

Active restoration could achieve two objectives. Sowing fastestablishing native annual seeds could provide resilience against reinvasion by invasive alien plant species (Falk et al., 2013; Herron et al., 2013), but could also provide protection for enhanced establishment of native perennial species germinating from the seed bank (Padilla and Pugnaire 2006). Sowing seeds of species representing a mix of different fynbos guilds could overcome biotic thresholds to facilitate restoration of vegetation structure and diversity where certain of these components have been lost (Holmes 2002). Sowing shortly after a fire while smoke residue is still present on the soil surface will stimulate germination of smoke-stimulated seeds (Brown et al., 2003), but not seeds requiring a heat pulse of the intensity experienced during a fire (Jeffery et al., 1988; Hall et al., 2016). Pre-treatment of seeds by mimicking fire conditions can improve efficiency of seed sowing in fynbos (Hall et al., 2016), chaparral (Wilkin et al., 2013) and kwongan (Roche et al., 1997).

In addition to a depleted native seed bank, invasive plants can also alter soil chemistry (Yelenik et al., 2004; Fisher et al., 2006; Marchante et al., 2008). This may result in native vegetation failing to establish either due to competition from secondary invasive species (Pearson et al., 2016; Nsikani et al., 2018) which take advantage of these conditions, or due to native species' sensitivity to toxicity effects resulting from altered soil chemistry (Witkowski 1991).

Studies concerning the use of fire in invasive plant management are lacking within the lowlands of the Cape fynbos, being mostly limited to mountain catchments (Holmes et al., 2000; Holmes and Marais 2000; Holmes and Cowling 1997b; Blanchard and Holmes 2008). Similar studies have also been conducted in Californian chaparral (Moyes et al., 2005; Alexander and D'Antonio 2003). Furthermore, limited work has been done to assess the effectiveness of active restoration in fynbos (Gaertner et al., 2012b; Waller et al., 2016; Pretorius et al., 2008), while pre-sowing seed treatment has been poorly studied. Effectiveness of active restoration has been studied in chaparral (Cione et al., 2002), while the incorporation of pre-sowing seed treatments has been tested in field trials in kwongan (Rokich and Dixon 2007).

Although science can inform best practise, there are also many constraints from a management and resource perspective (eg. Hewitt et al., 2005; Krupek et al., 2016). This is being solved through collaborations between scientists and management practitioners in studies such as this. A decision tree was developed based on the findings of this study in order to make this information accessible to managers involved in ecological restoration. The aims of this study were: (1) to determine whether biotic constraints exist to fynbos restoration following passive acacia clearing; (2) to determine whether abiotic constraints exist to fynbos restoration that hinder recovery in spite of sowing seed representing vegetation structural components; (3) to assess which treatment is most successful ecologically and develop a decision tree of best ecological restoration protocols.

We examined the following hypotheses: (i) Burning after clearing will effectively stimulate fynbos germination where native seed banks still exist, but poor fynbos recovery could result from depleted native seedbanks due to the impact of acacia invasion . (ii) Fynbos will re-establish following seed sowing thus showing that restoration is not limited by biotic or abiotic constraints. (iii) Passive clearing without burning will be successful where fynbos cover and diversity has persisted; if not then sowing seed after burning will be most successful ecologically. Optimal outcomes will be incorporated into the decision tree.

In order to investigate our aims, biotic constraints were determined by comparing vegetation recovery between passive and active restoration treatments, while abiotic constraints were determined by comparing vegetation recovery as well as soil chemistry (where possible) between active restoration treatments and reference sites. Restoration success was determined by comparing vegetation recovery under all treatments with reference site vegetation.

\section{Methods}

\subsection{Field site description}

The field site at Blaauwberg Nature Reserve is located within the largest remaining area of critically endangered Cape Flats Sand Fynbos, just north of urban Cape Town, South Africa $\left(33.75^{\circ} \mathrm{S}, 18.48^{\circ} \mathrm{E}\right)$ (Fig. 1). This vegetation type is confined to deep sandy soil of low $\mathrm{pH}$ at low altitudes, within a strongly Mediterranean climate region of hot, dry summers and cool, wet winters. Most of the vegetation was invaded by Acacia saligna, although standing cover of native species (mapped as restoration potential) varied greatly across the site (Fig. 2). A 64 hectare area was included in the study, incorporating mostly areas of very low $(<1 \%)$ and low $(1-10 \%)$ remaining fynbos vegetation cover, but also a few plots with medium (11-50\%) fynbos cover. These categories are generally accepted within local ecological expert opinion as appropriate for differentiating between restoration potential categories (Wotsitsa and Mgese 2012).

\subsection{Passive restoration experiment}

The 64 hectare restoration site was divided into two 32 hectare passive treatment blocks: stack-block treatment involved stacking cleared acacia biomass into brush piles, while burn-block treatment involved spreading biomass evenly and burning it. A prescribed fire was conducted in the burn-block treatment on 4th April 2013, within the optimal season to burn for fynbos recruitment (Van Wilgen and Viviers 1985). 


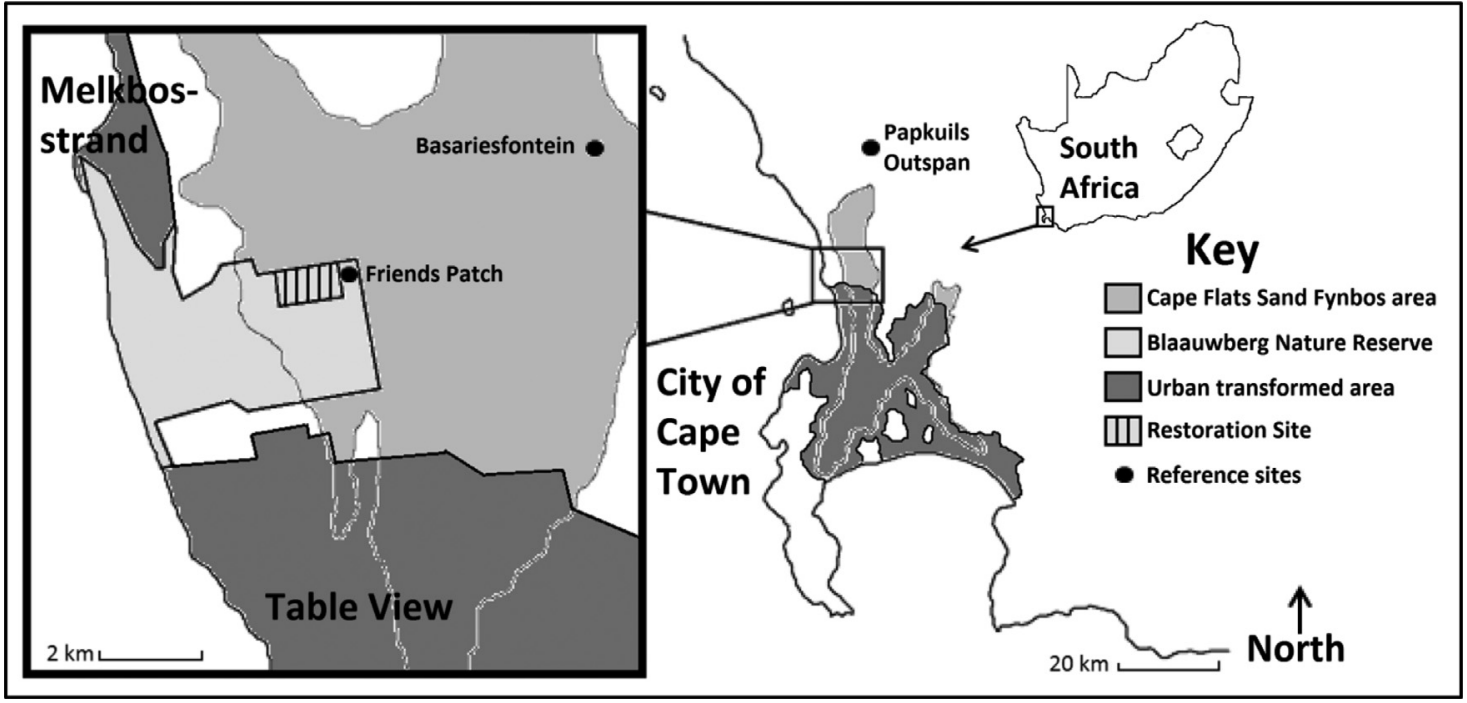

Fig. 1. Location of the study area at Blaauwberg Nature Reserve and reference vegetation sites north of the city of Cape Town, within the Western Cape province of South Africa.

Sixty four plots of $5 \times 10$ metres were established on a hectare grid pattern across the site with 32 plots in each passive treatment. These were monitored for vegetation richness (species/plot), cover (\%) and plant density (plants $/ 5 \mathrm{~m}^{2}$ ) of native and alien plant guilds at six month intervals (autumn and spring) for two years after initiating treatments in March 2013.

Soil chemistry data were sampled by collecting six replicate soil cores per plot in all restoration (64 plots) and reference sites (9 plots) and combining into one sample per plot. Soil samples were then analysed at Bemlab (Pty) Ltd. (Somerset West, South Africa) for available phosphorus (P, mg/kg, PBray II), mineral nitrogen (ammonium, NH4$\mathrm{N}, \mathrm{mg} / \mathrm{kg}$, and nitrate; NO3-N, mg/kg), electrical conductivity (EC, $\mathrm{mS})$, percentage carbon $(\% \mathrm{C})$ and nitrogen $(\% \mathrm{~N})$. Soil $\mathrm{pH}$ was analysed at Stellenbosch University, using a $0.01 \mathrm{M} \mathrm{CaCl}_{2} \bullet 2 \mathrm{H}_{2} \mathrm{O}$ solution $(25 \mathrm{~mL})$ and the $\mathrm{pH}$ of the supernatant was measured with a $\mathrm{pH}$ meter. Soil chemistry was sampled at the time of initiating treatments in March 2013 and again after one year in March 2014.

The sizes of native and acacia seed banks were determined by collecting six replicate soil cores per plot within both passive treatment sites. Replicate samples were combined and sieved to collect and count acacia seeds, then divided between two seed trays of $240 \times 170 \times 60 \mathrm{~mm}$ for each plot. Each plot's sample therefore represented $0.012 \mathrm{~m}^{2}$ of surface area, or $0.75 \mathrm{~m}^{2}$ including all plots. Trays were treated by exposing soil samples to smoke residue to stimulate germination of seeds in the soil (Brown 1993), after which they were placed into a greenhouse with open sides to maintain ambient temperature but with a constant irrigation regime of three times per week. Trays were then monitored for native seedling germination at weekly intervals for five months from June until October. Samples were collected at the time of initiating treatments for native and acacia seed bank as well as one and two years after initial clearing to determine acacia seed bank reduction rate.

\subsection{Active restoration experiment}

Two sowing plots of $9 \times 4 \mathrm{~m}$ were laid out perpendicular to each of the $5 \times 10 \mathrm{~m}$ monitoring plots in the 32 hectares under the burnblock treatment. One sowing plot was sown with an annual forb seed mix. The other was sown with a mix of species representing fynbos structural components including serotinous overstorey proteas, ericoid shrubs, Restionaceae (hereafter restios) and geophytes. Within these were a number of both resprouting and obligate re-seeding taxa. Seeds were collected from within a $10 \mathrm{~km}$ radius of the restoration site. Perennial fynbos species were selected to represent a range of vegetation structural components, growth-forms and seed morphologies (Hall et al., 2016). Sowing took place after the prescribed burn at the end of April 2013 to allow for high temperature fluctuation between day and night, since widely alternating diurnal temperatures stimulate germination in some species (Pierce and Moll 1994). Plots were monitored for vegetation richness (species/plot), cover (\%) and plant density (plants $/ 5 \mathrm{~m}^{2}$ ) of native and alien plant guilds at six month intervals (autumn and spring) for two years after sowing.

An additional sowing experiment was done a year after the initial active restoration treatment, in order to determine whether seed

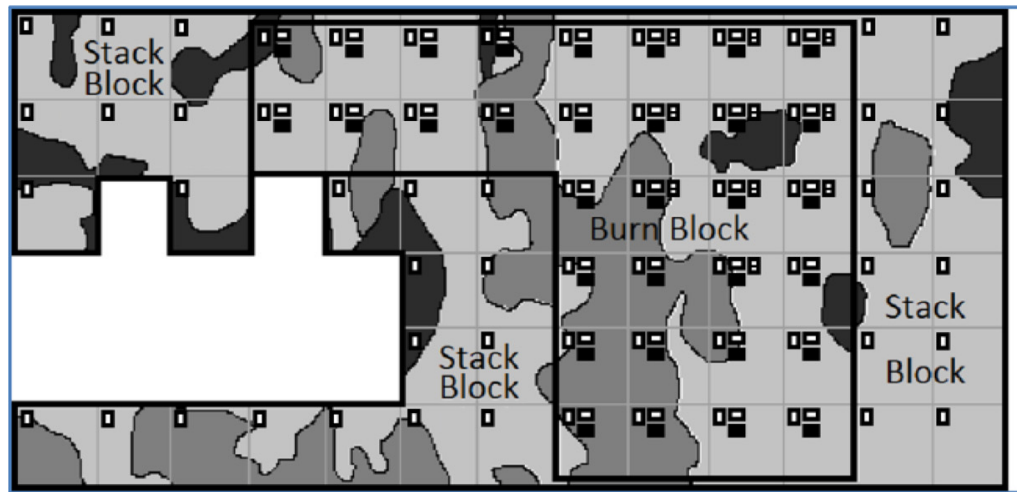

\begin{tabular}{l} 
Key \\
Restoration potential \\
$\square$ Medium (10-50\% indigenous cover) \\
$\square$ Low (1-10\% indigenous cover) \\
$\square$ Very Low (<1\% indigenous cover) \\
Field treatment plots \\
प Monitoring plot \\
D Annual sowing plot \\
- Fynbos sowing plot \\
D Delayed sowing plot \\
\hline 100 metres
\end{tabular}

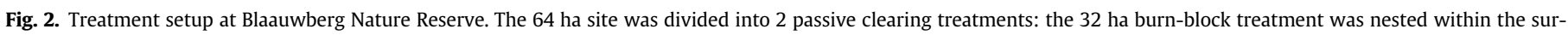
rounding stack-block treatment. Active sowing treatments were set up within burn-block plots. 
pre-treatment improves seed germination in the field. This involved a similar fynbos seed mix but with two plots, one sown with untreated seeds as before and one plot with seeds pre-treated with a combination of smoke solution and heat treatment. Species were treated based on seed germination requirement data (Brown 1993; Hall et al., 2016). Plots were surveyed using the same method as the other treatments but for two years after initiation of this treatment three years after initial clearing.

\subsection{Reference sites}

One patch of good quality fynbos vegetation adjacent to the restoration site within Blaauwberg Nature Reserve (Friends Patch) $33^{\circ}$ $45^{\prime} 09^{\prime \prime} \mathrm{S} 18^{\circ} 29^{\prime} 35^{\prime \prime} \mathrm{E}$, as well as nearby Papkuils Outspan $33^{\circ} 32^{\prime} 00^{\prime \prime} \mathrm{S}$ $18^{\circ} 30^{\prime} 00^{\prime \prime} \mathrm{E}$ were used as reference sites free of acacia invasion to compare with restoration treatments as a measure of success. Five plots were established in mature vegetation at Blaauwberg, and five plots were established in young vegetation recruiting after a 2013 fire at Papkuils Outspan to determine rates of pristine vegetation recovery post-fire. Reference plots were monitored for the same vegetation and soil chemistry data as in the restoration site, although mature fynbos plots were surveyed only once.

\subsection{Statistical analysis}

The Acacia seed bank data were shown to be normally distributed. Acacia seed density across the 32 plots per treatment was analysed over the three time periods to compare between stack-block and burn-block treatments. This was done using a repeated measures ANOVA as well as by performing a Fisher LSD post-hoc test in STATISTICA (version 13).

Soil chemistry data were shown to be normally distributed. To provide a comparison between stack-block and burn-block treatments as well as with the reference sites soil chemistry variables were analysed across the 32 plots per treatment, using an ANOVA, followed by a Fisher LSD test. Block-burn treatments were compared with the burnt reference site at the same times following the fire, while the stack-block treatment was compared with the initial unburnt reference site immediately after initial clearing as well as one year post-clearance .

All passive and active clearing treatments were compared by performing a repeated measures ANOVA for all treatments (Stack block SB, Burn block - BB, Fynbos sown - FS, Annual sown - AS, Fynbos sown pre-treated seed - FST, Fynbos sown untreated seed - FSUT) at all survey times (Initial, 6 months, 1 year, 18 months, 2 years) for the variables percentage cover, plant density and species richness. Burnblock and stack-block treatments were compared with reference site data using the same analyses. Stack-block treatment was compared with mature unburnt fynbos vegetation while burn-block treatment was compared with vegetation of the same age post-fire at each survey time. Data that were not normally distributed were transformed using a BoxCox transformation. Significance values were determined by performing a Fisher LSD post-hoc test in STATISTICA (version 13). In all analyses, differences were reported as significant where $p<$ 0.05 .

\section{Results}

\subsection{Biotic constraints to fynbos restoration}

\subsubsection{Native seed bank study}

Native soil seed banks across the restoration site were extremely species-poor with only 21 species recorded, of which only two were perennials each represented by an individual seedling. The density of the total native perennial seed bank was estimated to be $0.44 / \mathrm{m}^{2}$, versus geophyte density of $1.76 / \mathrm{m}^{2}$ represented by six species (emerged from soil stored corms), annual forb density of $11.22 / \mathrm{m}^{2}$ represented by nine species, and graminoid density of $4.62 / \mathrm{m}^{2}$ represented by four species. The latter two groups were dominated by alien species associated with disturbance. Soil seed banks from reference sites could not be determined due to an irrigation malfunction where these samples were kept causing seedlings to be killed before they could be identified. However, Holmes et al. (2002) found good representation of fynbos shrub diversity in seed bank studies within uninvaded sand fynbos sites. Furthermore, most of the species recorded in plots within the passive treatments were the same as those found in the native seed bank study.

\subsubsection{Acacia seed bank study}

There was a significant difference in the initial acacia seed bank size between treatments (Fig. 3). In the burn-block treatment there was a large decrease in the acacia seed bank following burning, but the seed bank did not decrease significantly after the first year following fire. The acacia seed bank size under the stack-block treatment also decreased following clearing but by a smaller amount initially. In the second year after clearing there was a further decrease, after which the seed bank size was not significantly different between the two passive treatments.

\subsection{Biotic constraints to fynbos restoration}

\subsubsection{Soil chemistry comparisons between passive treatments}

Changes in $\mathrm{NH}_{4}^{+}$, total $\mathrm{N}$, and Electrical Conductivity (EC) (Fig. 4) (as well as soil $\mathrm{pH}$ and total $\mathrm{C}$ (Appendix 1a, b)) did not differ between treatments and between initial clearing and one year post-clearing. $\mathrm{NO}_{3}{ }^{-}$remained stable over time in the stack-block treatment but decreased during the first year post-fire in the burn-block treatment. $P$ remained stable in the burn-block treatment while there was a decrease over time in the stack-block treatment (Fig. 4). Soil moisture was initially lower in the stack-block treatment than the burn-block, but in both treatments this dropped to a similar value after a year (Appendix 1c).

In the burnt reference site, $\mathrm{P}, \mathrm{NO}_{3}{ }^{-}, \mathrm{NH}_{4}{ }^{+}$, Soil $\mathrm{C}$ and soil moisture remained constant over time, while total $\mathrm{N}$ and EC decreased. In the burn-block treatment, $\mathrm{P}$ and $\mathrm{N}$ remained higher than the reference site a year after burning. In the stack-block treatment, soil moisture

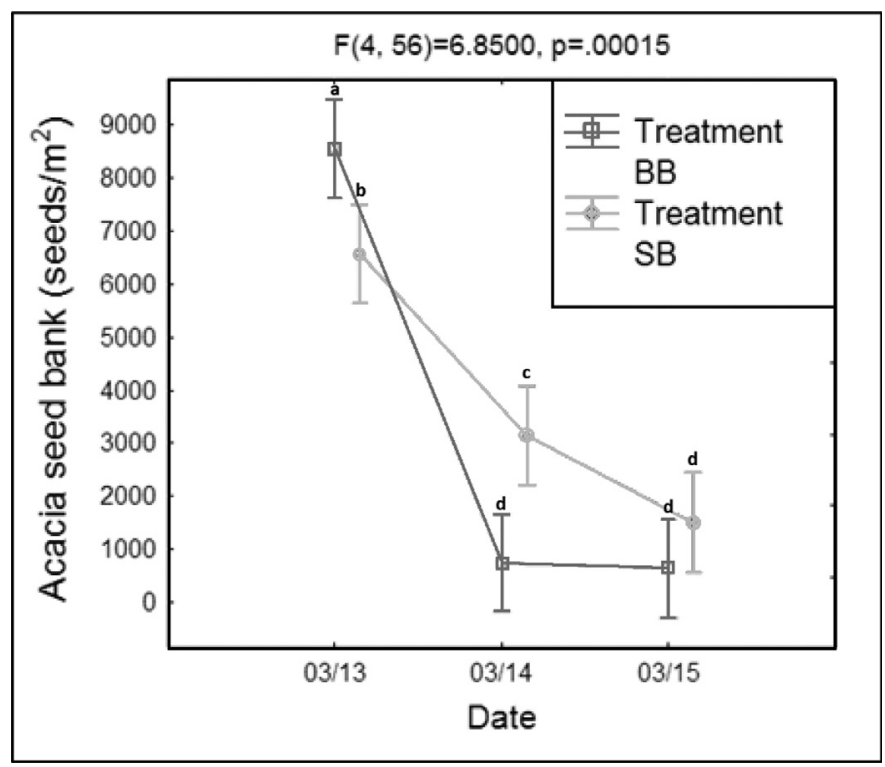

Fig. 3. Change in acacia seed bank over two years after initial clearing for passive treatments burn-block (BB) and stack-block (SB) analysed using ANOVA. Vertical bars denote 0.95 confidence intervals. 


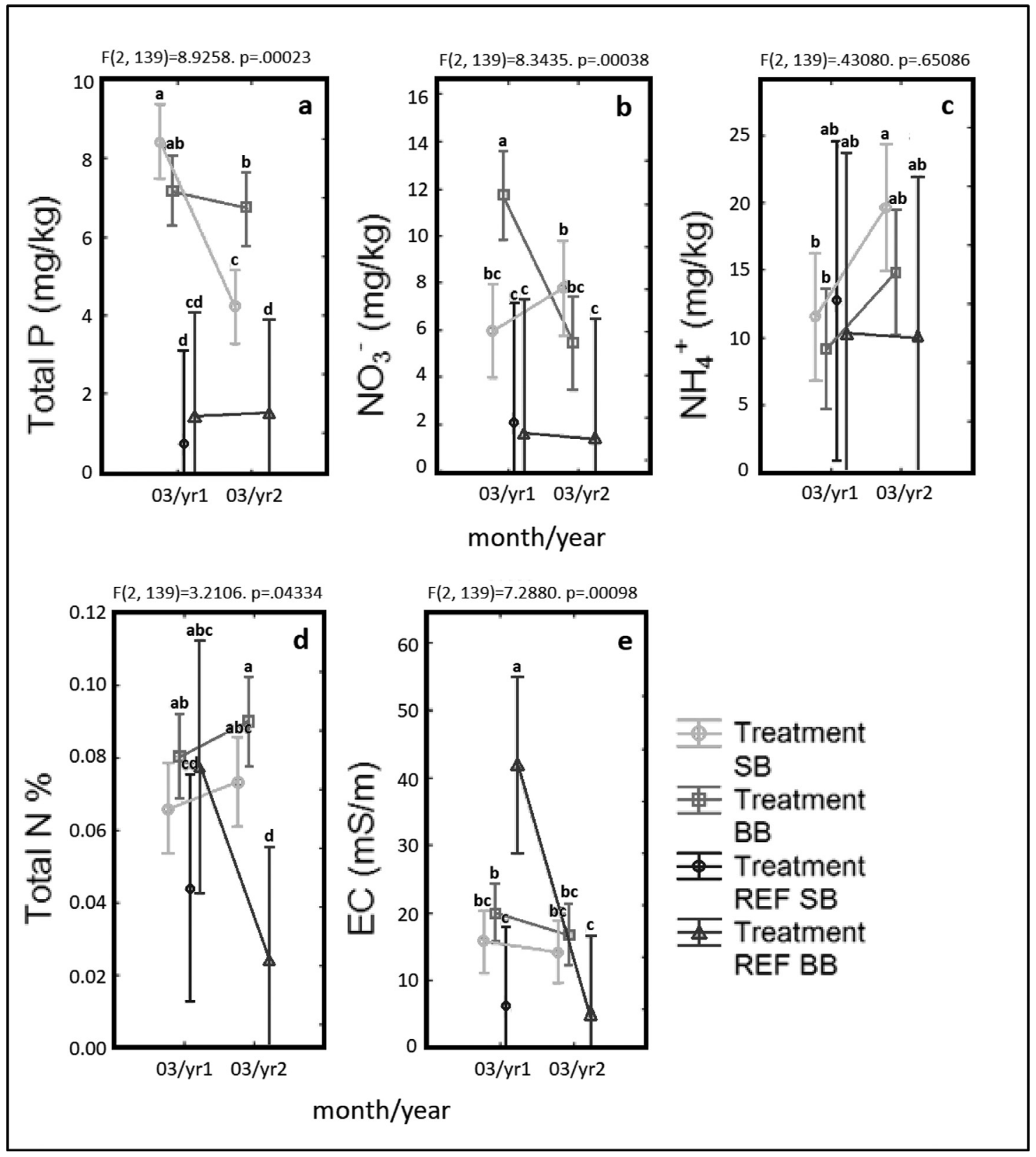

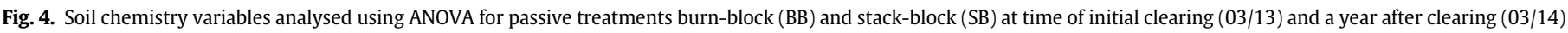
as well as burnt reference (REF BB) and mature reference vegetation (REF SB). Vertical bars denote 0.95 confidence intervals.

and soil carbon showed the same response as with burning, but $\mathrm{NO}_{3}$ as well as total $\mathrm{N}$ increased within a year after initial clearing to higher levels than in the unburnt reference site. $\mathrm{P}$ remained higher than the reference site since clearing (Fig. 4), while $\mathrm{NH}_{4}{ }^{+}$and EC did not differ over time.

It was intended that the relation between soil chemistry and fynbos growth would be further analysed. However no significant correlation was found between any of the soil chemistry variables and any of the vegetation growth parameters. Therefore further analyses were excluded from the current study.

\subsection{Restoration treatment effectiveness}

\subsubsection{Recovery of vegetation components under passive restoration} treatments

The stack-block treatment resulted in higher cover of alien annual graminoids (Fig. 5a) than the burn-block during spring surveys.
Invasive alien Acacia saligna cover (Fig. 5b) was lower under the stack-block treatment than all other treatments. Perennial graminoid cover (Fig. 5c) was lower in the burn-block initially but after a year had increased to the level of the stack-block. The stack-block treatment had higher cover of non-sprouting shrubs (Fig. 5d) and lower cover of resprouting shrubs (Appendix $2 \mathrm{f}$ ) than the burn-block treatment from the second spring onwards. Overall native species richness (Fig. 5f) was higher after two years in the burn-block than in the stack-block treatment, although much of the richness in both treatments consisted of annual species.

In comparison with the mature reference vegetation site, native perennial forb richness was higher in the stack-block treatment (Fig. 6a, b). Non-sprouting shrub densities were comparable to the reference site (Fig. 6c), but cover (Fig. 6d) was significantly lower in the stack-block treatment.

The burn-block treatment did not differ from the burnt reference site in terms of graminoid cover (Fig. 7a). All other vegetation 


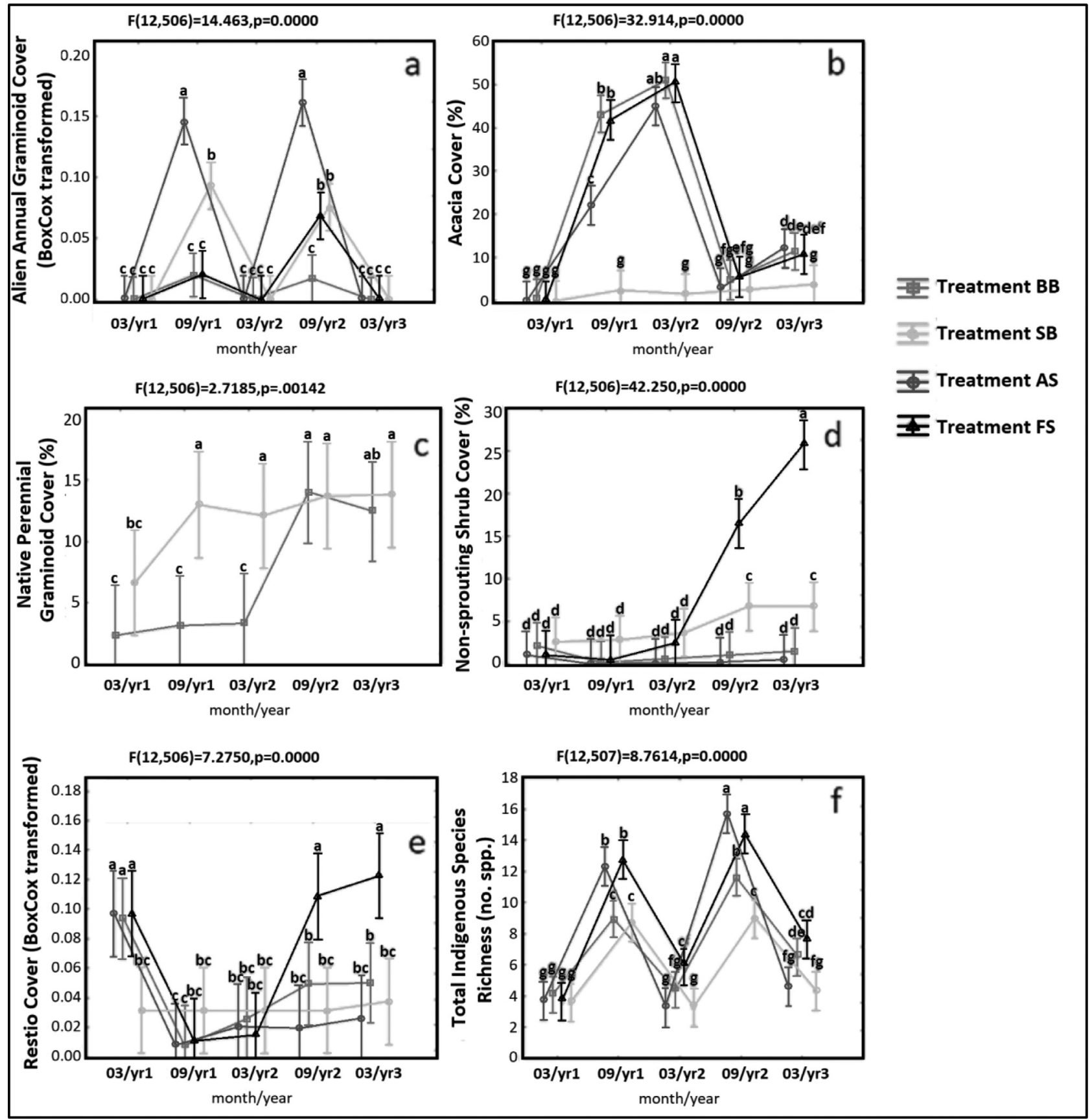

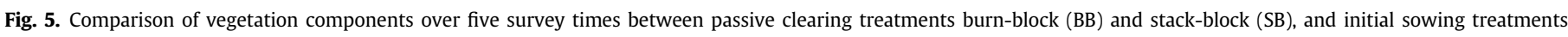

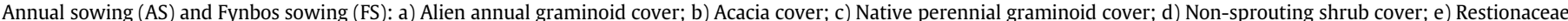

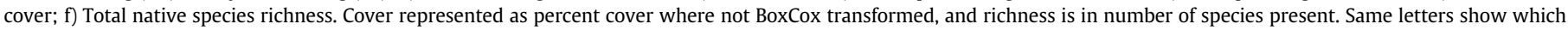
samples do not differ significantly based on repeat measures ANOVA. Vertical bars denote 0.95 confidence intervals.

components were significantly lower in the burn-block, as shown by lower total native cover (Fig. 7c). Apart from annual graminoid species richness (Fig. 7b), all other vegetation components had lower species richness in the burn-block treatment (Fig. 7d) than the burnt reference site.

\subsubsection{Recovery of vegetation components under initial active restoration treatments}

Sowing of annuals resulted in higher alien annual graminoid cover (Fig. 5a) during spring surveys, and initially lower acacia cover (Fig. 5b) compared to other burn block treatments. Annual sown plots had highest native annual forb cover and species richness, although cover declined in the second year.
Non-sprouting shrub cover (Fig. 5d) as well as Restionaceae cover (Fig. 5e), density and richness was highest in fynbos-sown plots from the second spring but non-sprouting richness and density was higher at all times after burning and sowing.

\subsubsection{Follow-up sowing treatments with untreated and pre-treated seed}

Follow-up sowing treatments showed no change in acacia cover over the duration of surveying, and did not differ at the end of the experiment from other burn-block treatments. Restio cover was higher in pre-treated compared to untreated and unsown plots from the second autumn onwards (Fig. 8a). Restio density was initially highest for pre-treated sown plots, but then decreased and did not 


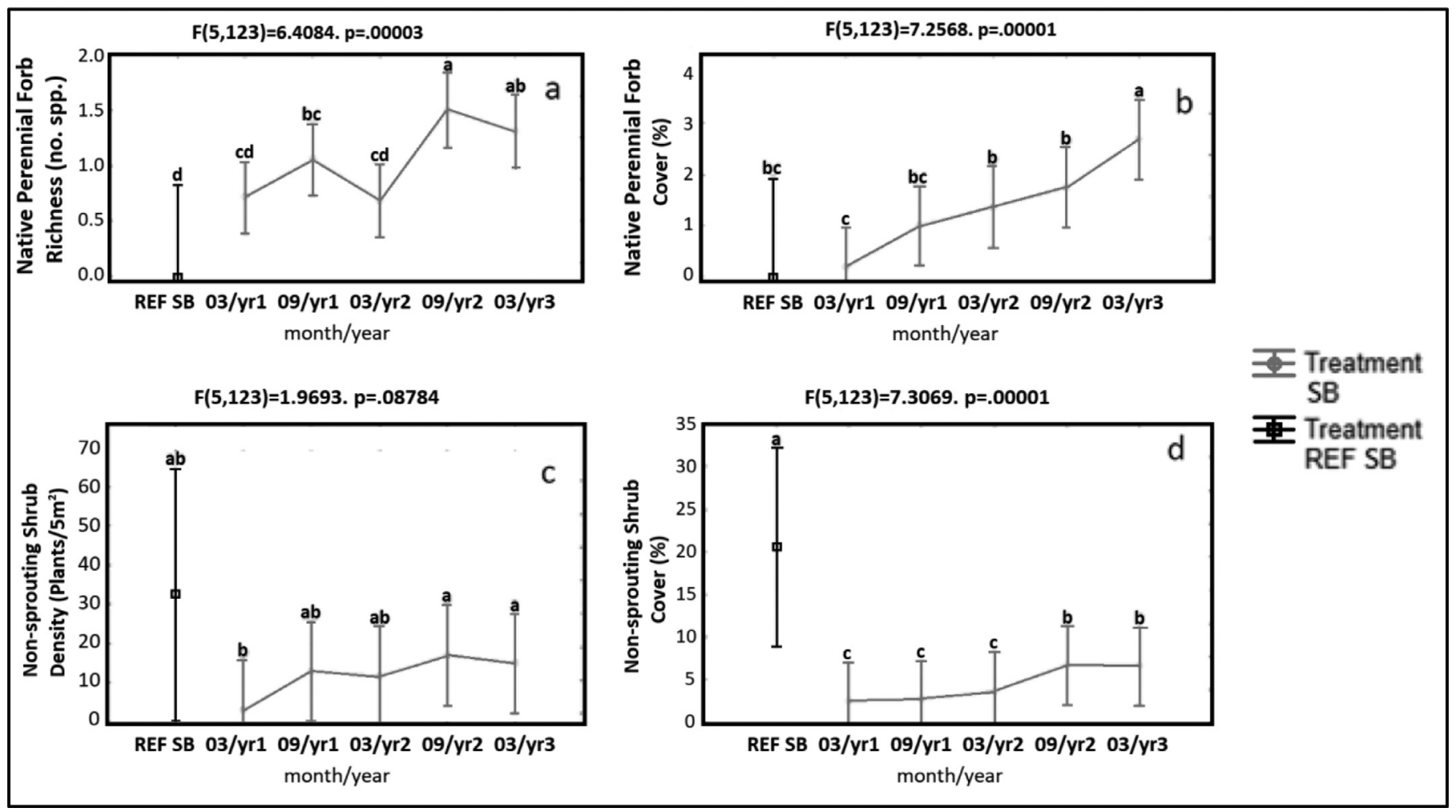

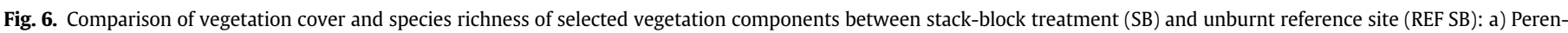

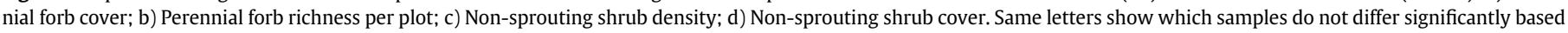
on repeat measures ANOVA. Vertical bars denote 0.95 confidence intervals.

differ from the untreated sown plots after the second winter (Fig. 8b). Resprouting shrub cover was higher in pre-treated sown plots than un-treated sown plots during the first spring, but was higher than the initial sowing treatment at all times after the initial survey (Fig. 8c). Resprouting shrub richness of both follow-up sowing treatments was higher than initial sowing treatment (Fig. 8d). Nonsprouting shrub cover increased equally in both follow-up sowing treatments, and was higher than initial sowing treatment after two years (Fig. 8e). Nonsprouting shrub density was highest in the pretreated sowing treatment in the first spring survey, after which densities in all sowing treatments were the same (Fig. 8f).

\section{Discussion}

The main aims of this study were to determine the most effective passive and active restoration techniques in overcoming constraints to restoration of Cape Flats Sand Fynbos. Burning after clearing did not facilitate better fynbos recruitment than clearing alone within the majority of the treatment plots. Passive restoration is seed-limited since seed banks are depleted and thus a biotic threshold was crossed. The study supported the hypothesis that sowing seeds improves fynbos establishment, thereby overcoming the constraint of seed-limitation (Fig. 9).

While all treatments differed from each other after two years, no treatment resembled the reference vegetation structure. Two years is perhaps insufficient to easily assess treatment success in restoring vegetation structure, since different vegetation components dominate at different points in time following disturbance (Hoffman et al., 1987). However, within two years following fire all species in a fynbos community should be present since most fynbos species have seeds that germinate in response to fire-related cues (Le Maitre and Midgley 1992). Therefore it appears that none of the tested treatments will necessarily facilitate restoration of a pristine ecosystem even in the long-term. This is supported by the results from having developed a model using this data to predict long-term recovery trajectories (Hall et al., 2020).

\subsection{Biotic constraints to fynbos restoration following passive acacia clearing}

The seed bank study indicated that native seed banks lacked the expected density and diversity of perennial species at the time of clearing, as has been reported previously following alien invasion (Holmes 2002). Native seed bank depletion has also been found in acacia-invaded Portuguese dune ecosystems (Marchante et al., 2011a) as well as in grass-invaded Californian coastal shrubland (Cione et al., 2002), in both cases suggesting that biotic thresholds may have been crossed.

In our study, non-sprouting shrub cover increased within the stack-block treatment after two years due to recruitment of seedlings of a few species not requiring fire-related cues for germination (Hall et al., 2016). In time this could facilitate recovery of shrub cover, but since most fynbos species are only capable of short-distance dispersal (Holmes and Cowling 1997a) it is unlikely that there would be an increase in shrub species richness with time, even after subsequent fires.

Burning after clearing resulted in minimal recovery of nonsprouting native shrub species, due to a combination of a depleted native seed bank, and competition from vigorous post-fire recruitment of Acacia saligna (Holmes 2002; Musil 1993) since this species is stimulated to germinate by fire. A similar phenomenon has been found in ecosystems with different invasive species (Yurkonis et al., 2005). However, depleted seed banks are more likely responsible than post-recruitment acacia competition, since it was noted in some parts of the burn block treatment that a diversity of native shrub seedlings had established despite dense acacia recruitment. Most native shrub recovery in passive treatments was limited to established plants persisting at the time of initial clearing. 


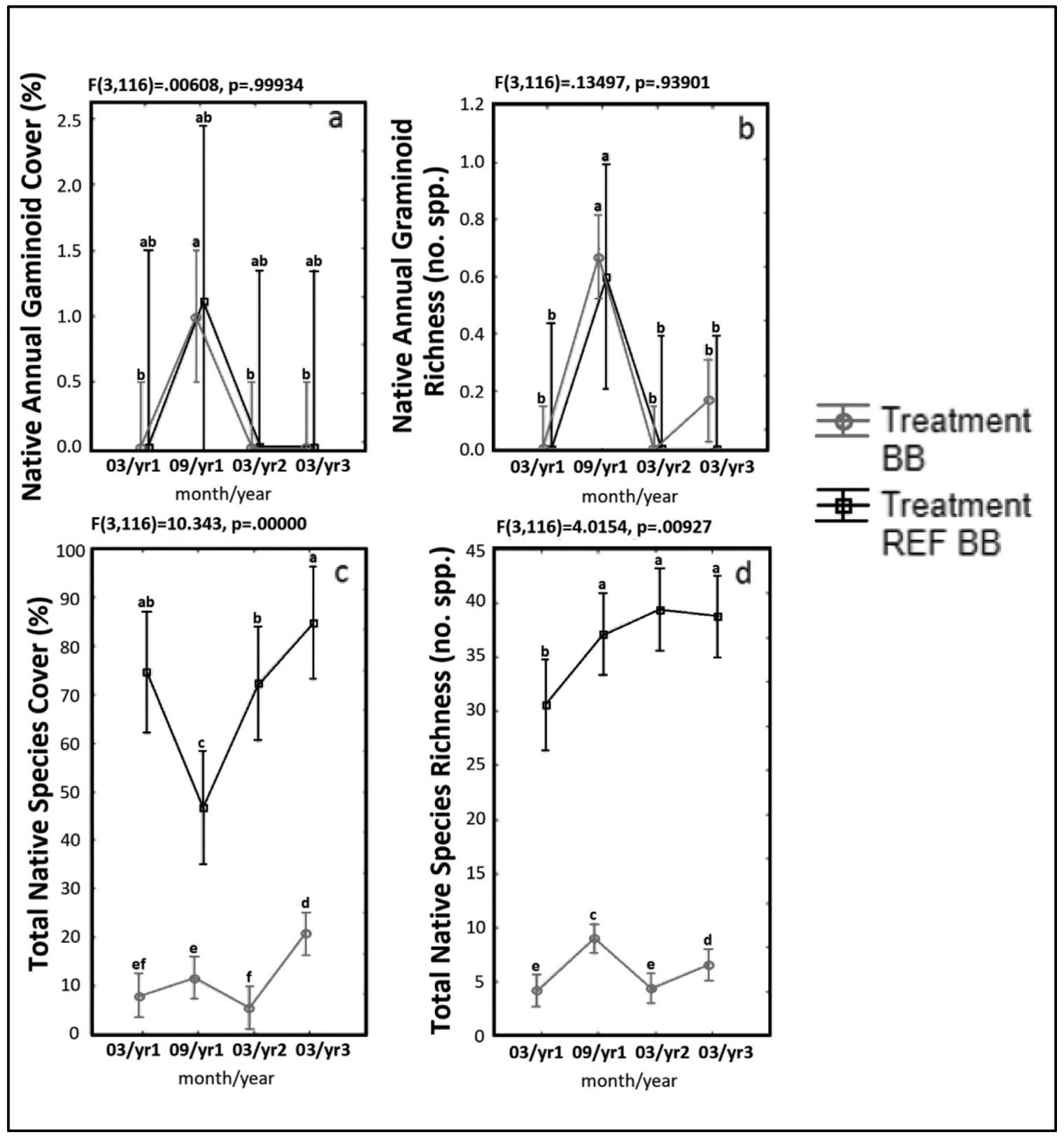

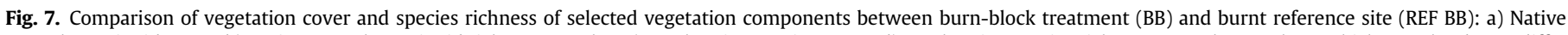

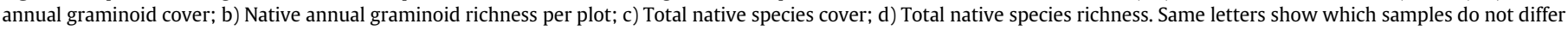
significantly based on repeat measures ANOVA. Vertical bars denote 0.95 confidence intervals.

Acacia densities were found by Holmes and Cowling (1997b) to have a significant negative impact on establishment success of shrub seedlings in sowing experiments. In follow-up sowing treatments, acacia cover and growth rate was much lower since follow-up clearing operations took place shortly before sowing. The motivation of burning before sowing was to clear litter from the soil surface which otherwise inhibits native seedling germination (Marchante et al., 2011b), and provide smoke residue to stimulate germination (Brown 1993), but the competitive effect of the high invasive seedling density (Adams and Galatowitsch 2008) outweighed potential benefits.

\subsection{Abiotic constraints to fynbos restoration and the impact of associated soil chemistry legacy effects}

Comparison of soil chemistry variables between each passive clearing treatment and the corresponding reference sites showed that legacy effects of certain soil chemistry variables remain after a year, as indicated by higher levels of $\mathrm{P}$ and $\mathrm{N}$ in cleared sites compared to reference sites. These findings correspond with those of Nsikani et al. (2017) who found that altered soil chemistry effects persisted for an extended time after acacia clearing. The elevated nutrient availability could negatively affect growth of some fynbos species including Protea repens (Witkowski 1991; Lamb and Klaussner 1988). However, Protea repens established within plots with no evidence of toxicity effects, and therefore it does not appear that an abiotic threshold had been crossed.

Lack of fire after clearing or lack of rapid native shrub establishment after burning left gaps for secondary invasive species to establish and dominate; in this case resulting in a persistent herbaceousdominated vegetation state before native shrub species could establish. Combined with increased nutrient availability, bare ground promotes invasion by alien annual grasses (Maron and Jefferies 1999), as well as opportunistic weedy native species including Ehrharta 

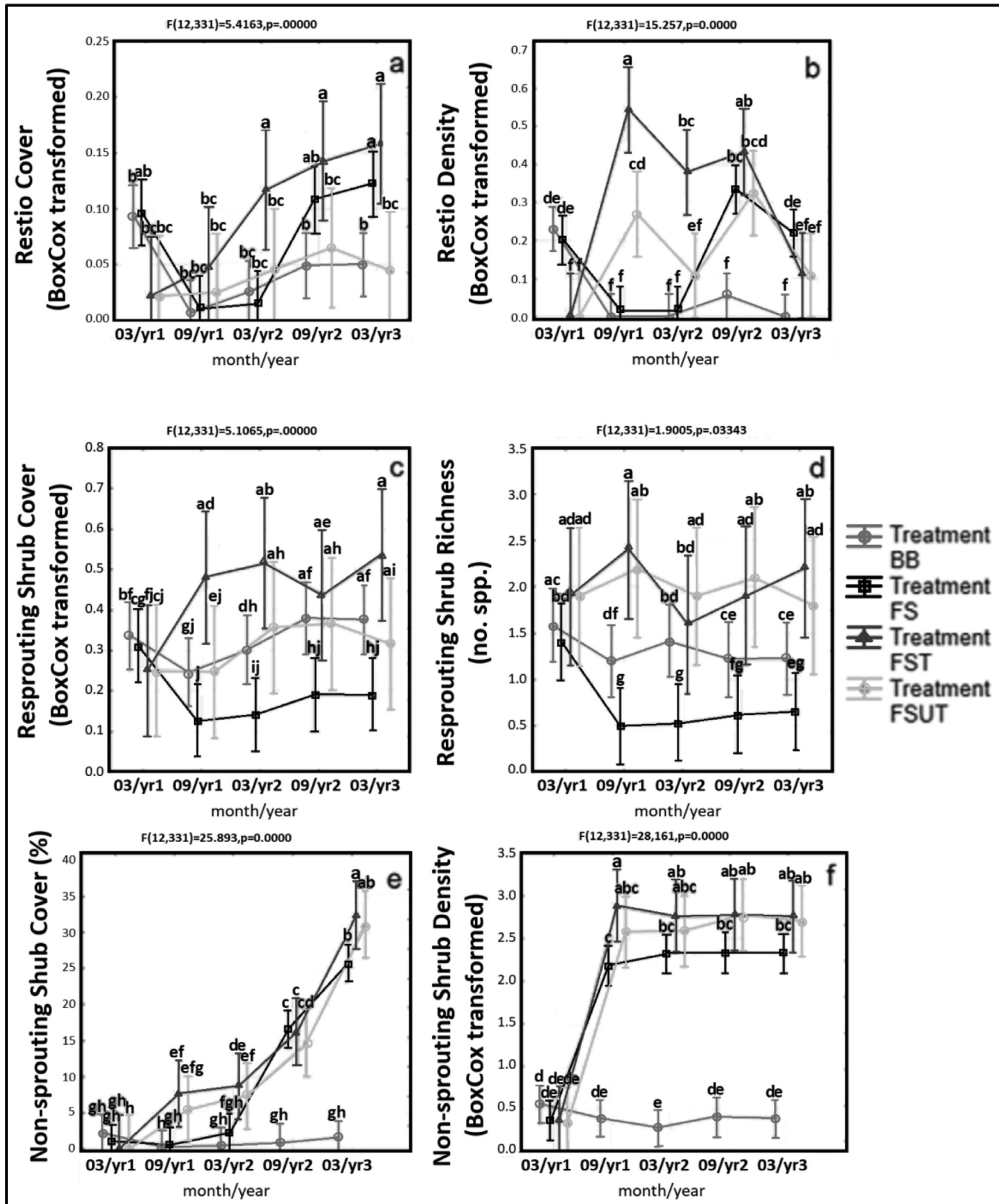

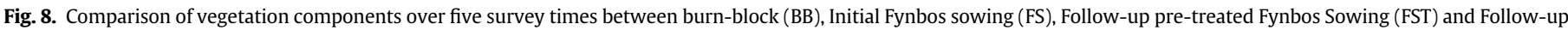

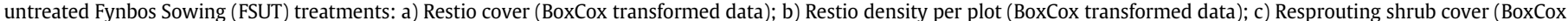

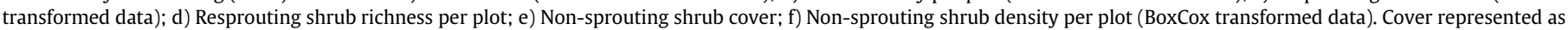

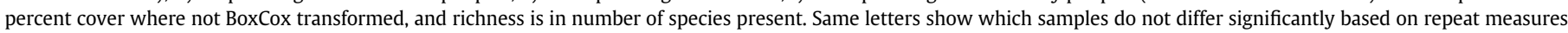
ANOVA. Vertical bars denote 0.95 confidence intervals. 


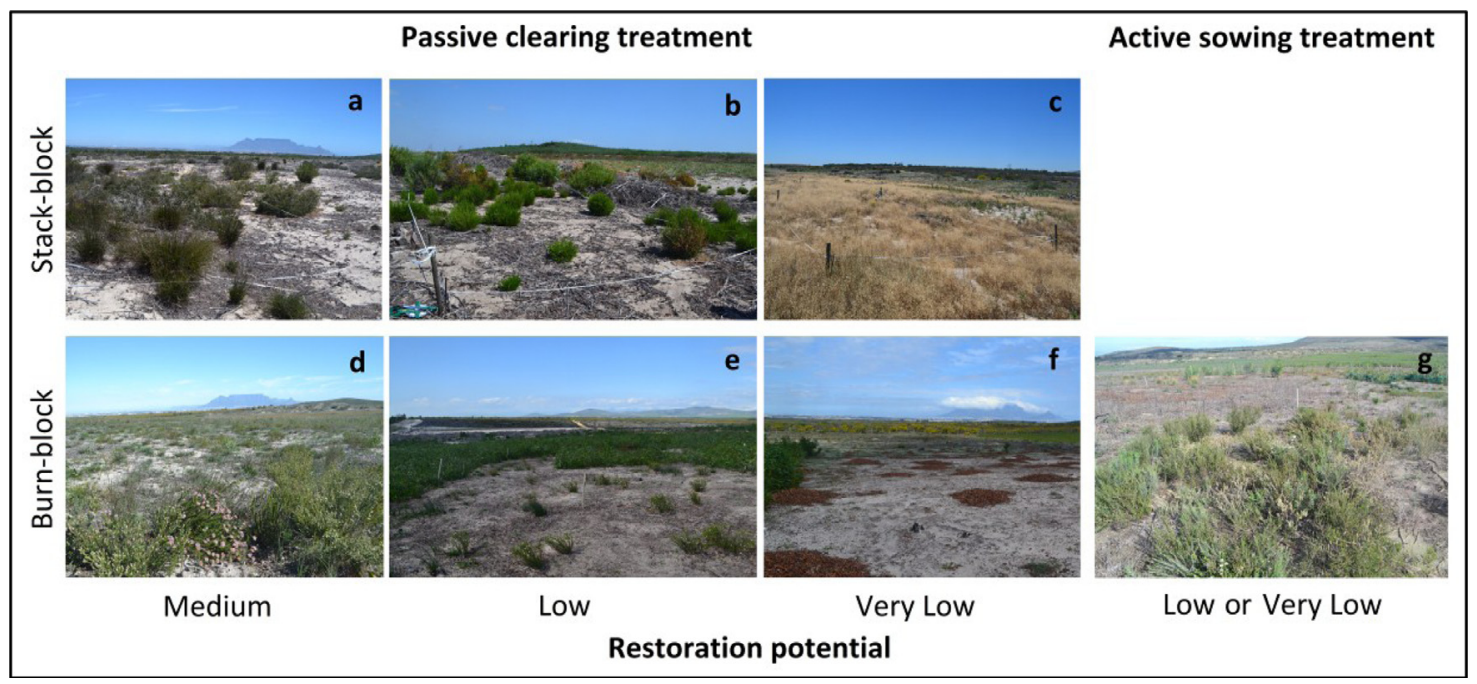

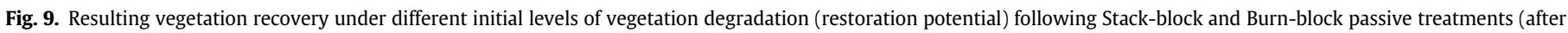

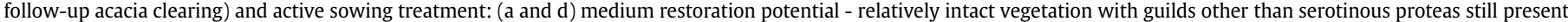

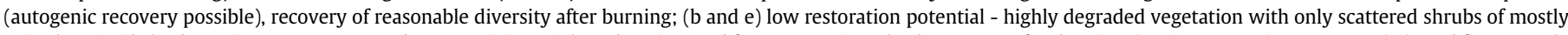

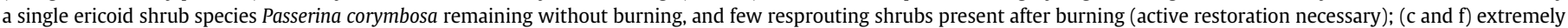

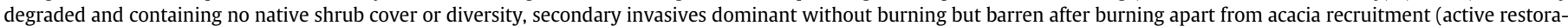

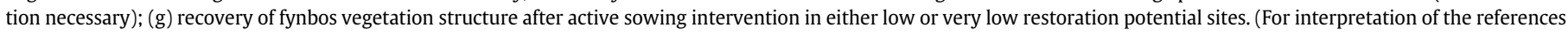
to colour in this figure legend, the reader is referred to the web version of this article.)

calycina (Yelenik et al., 2004; Fisher et al., 2006). These species compete against native shrubs which are unable to benefit from increased nutrients (Musil 1993). Grass-dominated vegetation is more prone to burning than native shrub cover (Cione et al., 2002), and these combined effects prevent reversal of this biotic threshold, resulting in a possible regime shift to another ecosystem state (Gaertner et al., 2014).

Reduced soil carbon within both passive treatments may be a limiting factor in facilitating excess $\mathrm{N}$ immobilization. Soil remediation through input of carbon-rich mulch can deplete excess nutrients in order to decrease competition from secondary invasive annuals and therefore facilitate establishment of less competitive native shrub species (Zink and Allen 1998; Gaertner et al., 2011).

\subsection{Assessment of the ecological effectiveness of restoration treatments}

The stack-block treatment was arguably most effective in terms of restoring a balance of different native vegetation components, although this depended on shrubs persisting before initial clearing (Fig. 9a). Bare ground was subsequently invaded by herbaceous species. Lack of fire hindered the recovery of many fynbos species requiring fire-related cues for germination (Holmes and Cowling 1997b). Acacia saligna recruitment would however also be hindered by lack of fire (Richardson and Kluge 2008), resulting in much lower costs for acacia follow-up clearing than the burn-block treatment. The acacia seed bank of the stack-block treatment was reduced by almost as much as the burn-block within three years of initial clearing, perhaps due to removal by rodents (Holmes 1990), showing that fire is not necessary for reducing acacia seed banks in this ecosystem following clearance of the alien stand.

Burning effectively controlled alien annual graminoids, suggesting that the heat of the fire killed their shallow seedbanks. Annual grasses were already apparent in the stack-block treatment but not in the burn-block before acacia seedlings germinated. Alien forbs were initially controlled in the burn-block treatment, but this was not sustained beyond one year after burning, likely due to reinvasion from the stack-block area and lack of competition after follow-up acacia clearing in the second winter. The decreased alien annual grass cover may also have facilitated establishment of alien forbs, as has been found following attempts to control alien grasses (Cox and Allen 2008). Sowing of native annual forbs can unintentionally spread secondary invasives if seed batches are contaminated with alien annuals, since higher overall alien herbaceous cover was found in the annual sowing treatment over the longer term. Along with higher native perennial forb cover, this resulted in establishment of herbaceous dominated vegetation rather than facilitating native shrub establishment and is therefore an undesirable treatment.

Pre-treating restio seeds resulted in an initially higher number of plants, which subsequently decreased after the following summer, suggesting that drought stress hampers optimal restio establishment from seed. Resprouting species are not entirely dependent on seeds for maintaining populations (Van Wilgen and Forsyth 1992) and exhibit very low recruitment rates (Marais et al., 2014). However, pre-treated seeds of Phylica cephalantha and Trichocephalus stipularis showed high germination success under laboratory conditions (Hall et al., 2016), thus poor establishment success following pretreatment suggests that there are post-germination barriers in the field.

Drought sensitivity has been found to hinder shrub establishment from seeding treatments (Cione et al., 2002; Moreno et al., 2011). Higher establishment success could be achieved through supplemental watering after sowing seeds (although only practical on a small scale). Watering may benefit secondary invader establishment, but could facilitate more rapid native cover establishment (Daehler and Goergen 2005). However, the large scale of restoration efforts required coupled with a lack of local water supply render irrigation unfeasible. It may be more effective to aim for optimal germination of available seed through pre-treatment before sowing, or sowing pre-treated seeds over multiple years if the first year is unusually dry.

Resprouting and restio species may also establish more successfully by planting out rootstock which have sufficient resources to establish before the following summer. Rootstock planting has achieved limited success in Australia, although the plants which survived showed very poor reproductive success (Morgan 1999). Reintroductions of threatened species by planting seedlings have been successful in Tokai Park within Cape Flats Sand Fynbos (Hitchcock and Rebelo 2017), although reproductive success at this 


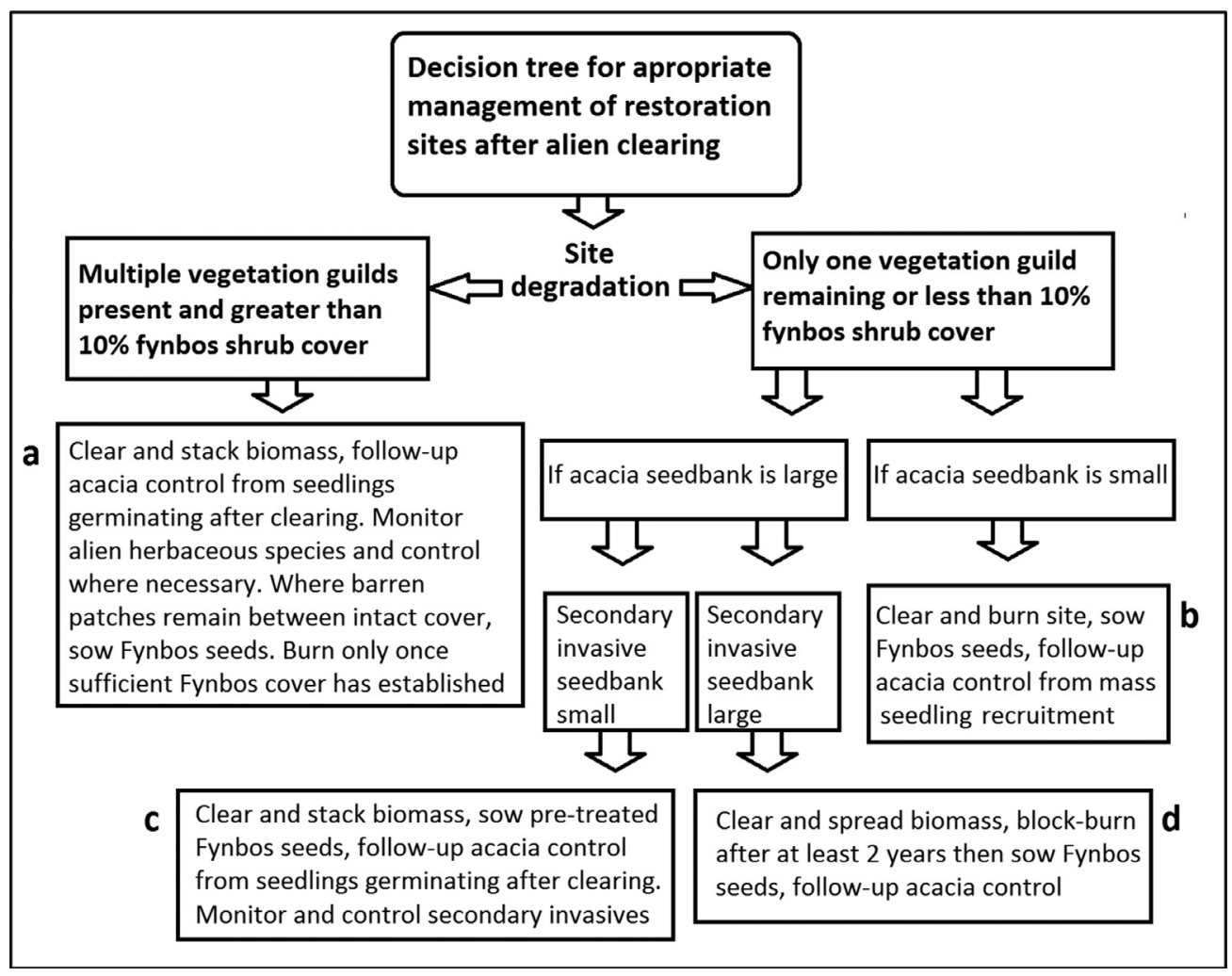

Fig. 10. Decision tree for determining best protocol for restoration of lowland fynbos vegetation after initial alien clearing.

site appears to have been comparable to reference sites for some species studied (Hall unpublished).

\subsection{Development of a decision tree to determine best protocols for restoration}

The most effective restoration method depends on site-specific characteristics. The knowledge developed from this study has therefore been used to develop a decision tree to determine best protocols for restoration and guide managers carrying out this work in different sand fynbos areas (Fig. 10). Based on the treatments tested, where some fynbos vegetation structure remains at the time of acacia clearing, the stack-block passive treatment alone can be applied since native seed banks have likely not yet been depleted. Where vegetation structure has been lost by the time of clearing, native seedbanks will also have been depleted, and thus a biotic threshold may have been crossed. In such cases active restoration will be necessary. If plots are burned after clearing, delayed sowing with pre-treated seeds may be a better option than initial sowing as this allows acacia seedlings to be removed, and autogenic recovery can be better assessed prior to sowing. Alternatively, sowing pre-treated seeds without burning could be considered, if sufficient cleared alien biomass can be removed. However, in this case secondary invaders may compete with seedling establishment, but appropriate means of control can help decrease the competitive advantage until shrubs establish sufficient cover. Native vegetation can be restored following invasive alien removal, so long as consideration is given to the habitat state at the time of clearing.

\section{Conclusions}

Our hypotheses were supported overall. Firstly, burning after clearing alone generally failed to facilitate improved fynbos recovery within our study site. It appears that native soil seed banks have been depleted due to impacts associated with acacia invasion, which therefore suggests a biotic constraint to passive restoration. Secondly, we found that fynbos will establish following seed sowing thus showing that biotic constraints can be overcome through active restoration. Abiotic constraints appear not to have hindered restoration, although soil chemistry has been partially altered by acacia invasion. Pre-treatment of fynbos seed before sowing can further improve establishment success and therefore increase efficiency of this treatment. Under the conditions within our study site, active fynbos sowing treatment was the most effective of the treatments tested. However, the most effective treatment is likely to differ among sites, depending on the invasion history and proximity to natural vegetation remnants among other factors. The decision tree developed from our findings will assist in determining the best protocols for restoration based on local site conditions.

\section{Declaration of Competing Interest}

The authors declare that they have no known competing financial interests or personal relationships that could have appeared to influence the work reported in this paper.

\section{Acknowledgements}

Field experimental work and data collection was undertaken with financial support from the Millenium Seed Bank Partnership (Royal Botanical Gardens, Kew), DST-NRF centre of Excellence for Invasion Biology and Working for Water Programme through their collaborative research project on 'Integrated Management of invasive alien species in South Africa'. The large-scale restoration field experiment was set up in collaboration with the City of Cape Town Biodiversity Management Branch (BMB). We are particularly grateful to the Invasive Species Unit and the Blaauwberg Nature Reserve staff who resourced and supervised the 64 hectares of alien acacia clearance, as well as the many BMB staff who conducted the prescribed burn and assisted with native seed collections. Karen J. Esler and Patricia M. 
Holmes acknowledge funding from the Hans Hoheisen Charitable Trust.

\section{Supplementary materials}

Supplementary material associated with this article can be found, in the online version, at doi:10.1016/j.sajb.2020.12.020.

\section{References}

Adams, C.R., Galatowitsch, S.M., 2008. The transition from invasive species control to native species promotion and its dependence on seed density thresholds. Appl. Veg. Sci. 11, 131-138.

Alexander, J.M., D'Antonio, C.M., 2003. Seed bank dynamic of French broom in coastal California grasslands: effects of stand age and prescribed burning on control and restoration. Restor. Ecol. 11, 185-197.

Blanchard, R., Holmes, P.M., 2008. Riparian vegetation recovery after invasive alien tree clearance in the Fynbos Biome. S. Afr. J. Bot. 74, 421-431.

Brown, N.A.C., 1993. Promotion of germination of fynbos seeds by plant-derived smoke. New Phytol. 123, 575-583.

Brown, N.A.C., Van Staden, J., Daws, M.I., Johnson, T., 2003. Patterns in the seed germination response to smoke in plants from the Cape Floristic Region, South Africa. S. Afr. J. Bot. 69, 514-525.

Cione, N.K., Padgett, P.E., Allen, E.B., 2002. Restoration of a native shrubland impacted by exotic grasses, frequent fire, and nitrogen deposition in Southern California. Restor. Ecol. 10, 376-384.

Cox, R.D., Allen, E.B., 2008. Stability of exotic annual grasses following restoration efforts in Southern California coastal sage scrub. J. Appl. Ecol. 45, 495-504.

D'Antonio, C.M., Malmstrom, C., Reynolds, S.A., Gerlach, J., 2007. Ecology of invasive non-native species in California grassland, In: Stromberg, M.R., Corbin, J.D. D’Antonio, C.M. (Eds.), California Grasslands: Ecology and Management. University of California Press, California, pp. 67-83.

Daehler, C.C., Goergen, E.M., 2005. Experimental restoration of an indigenous Hawaiian grassland after invasion by buffel grass (Cenchrus ciliaris). Restor. Ecol. 13, 380389.

Falk, A.D., Fulbright, T.E., Smith, F.S., Brennan, L.A., Ortega-Santos, A.J., Benn, S., 2013. Does seeding a locally adapted native mixture inhibit ingress by exotic plants? Restor. Ecol. 21, 474-480.

Fisher, J.L., Loneragan, W.A., Dixon, K., Veneklaas, E.J., 2009. Soil seed bank compositional change constrains biodiversity in an invaded species-rich woodland. Biol. Conserv. 142, 256-269.

Fisher, J.L., Veneklaas, E.J., Lambers, H., Loneragan, W.A., 2006. Enhanced soil and leaf nutrient status of a Western Australian Banksia woodland community invaded by Ehrharta calycina and Pelargonium capitatum. Plant Soil 284, 253-264.

Gaertner, M., Richardson, D.M., Privett, S.D.J., 2011. Effects of alien plants on ecosystem structure and functioning and implications for restoration: insights from three degraded sites in South African fynbos. Environ. Manag. 48, 57-69.

Gaertner, M., Holmes, P.M., Richardson, D.M., 2012a. Biological invasions, resilience and restoration. In: Andel, J., Aronson, J. (Eds.), Restoration Ecology: The New Frontier. Wiley-Blackwell, Oxford.

Gaertner, M., Nottebrock, H., Fourie, H., Privett, S.D.J., Richardson, D.M., 2012b. Plant invasions, restoration, and economics: perspectives from South African fynbos. Perspect. Plant Ecol. Evol. Syst. 14, 341-353.

Gaertner, M., Biggs, R., Te Beest, M., Hui, C., Molofsky, J., Richardson, D.M., 2014. Invasive plants as drivers of regime shifts: identifying high-priority invaders that alter feedback relationships. Divers. Distrib. 20, 733-744.

Hall, S.A., Newton, R.J., Holmes, P.M., Gaertner, M., Esler, K.J., 2016. Heat and smoke pre-treatment of seeds to improve restoration of an endangered Mediterranean climate vegetation type. Austral. Ecol. 42, 354-366.

Hall, S.A., Bastos, R., Vicente, R., Vaz, A.S., Honrado, J.P., Holmes, P.M., Gaertner, M., Esler, K.J., Cabral, J.A., 2020. A dynamic modelling tool to anticipate the effectiveness of invasive plant control and restoration recovery trajectories in South African Fynbos. Restor. Ecol.. https://doi.org/10.1111/rec.13324.

Herron, C.M., Jonas, J.L., Meiman, P.J., Paschke, M.W., 2013. Using native annual plants to restore post-fire habitats in western North America. Int. J. Wildland Fire 22, 815-821.

Hewitt, C.L., Campbell, M.L., McEnnulty, F., Moore, K.M., Murfet, N.B., Robertson, B., Schaffelke, B., 2005. Efficacy of physical removal of a marine pest: the introduced kelp Undaria pinnatifida in a Tasmanian Marine Reserve. Biol. Invas. 7, 251-263.

Hitchcock, A., Rebelo, A.G., 2017. The Restoration of Erica verticillata - a Case Study in Species and Habitat Restoration and Implications for the Cape Flora. Sibbaldia: J. Bot. Garden Hortic. 15, 39-63.

Hoffman, M.T., Moll, E.J., Boucher, C., 1987. Post-fire succession at Pella, a South African lowland fynbos site. S. Afr. J. Bot. 53, 370-374

Holmes, P.M., 1990. Dispersal and predation of alien Acacia seeds: effects of season and invading stand density. S. Afr. J. Bot. 56, 428-434.

Holmes, P.M., 2002. Depth distribution and composition of seed-banks in alieninvaded and uninvaded fynbos vegetation. Austral. Ecol. 27, 110-120.

Holmes, P.M., Cowling, R.M., 1997a. Diversity, composition and guild structure relationships between soil-stored seed banks and mature vegetation in alien plantinvaded South African fynbos shrublands. Plant Ecol. 133, 107-122.
Holmes, P.M., Cowling, R.M., 1997b. The effects of invasion by Acacia saligna on the guild structure and regeneration capabilities of South African fynbos shrubland. J. Appl. Ecol. 34, 317-332.

Holmes, P.M., Esler, K.J., Van Wilgen, B.W., Richardson, D.M., 2020. Ecological restoration of ecosystems degraded by invasive alien plants in South African Fynbos: is spontaneous succession a viable strategy? Trans. R. Soc. South Africa 75, 111-139.

Holmes, P.M., Macdonald, I.A.W., Juritz, J., 1987. Effects of clearing treatment on seed banks of the alien invasive shrubs Acacia saligna and Acacia cyclops in the Southern and South-Western Cape, South Africa. J. Appl. Ecol. 24, 1045-1051.

Holmes, P.M., Marais, C., 2000. Impacts of alien plant clearance on vegetation in the mountain catchments of the Western Cape. Southern Afr. For. J. 189, 113-117.

Holmes, P.M., Richardson, D.M., 1999. Protocols for restoration based on recruitment dynamics, community structure, and ecosystem function: perspectives from South African fynbos. Restor. Ecol. 7, 215-230.

Holmes, P.M., Richardson, D.M., Van Wilgen, B.W., Gelderblom, C., 2000. Recovery of South African fynbos vegetation following alien woody plant clearing and fire: implications for restoration. Austral. Ecol. 25, 631-639.

Jeffery, D.J., Holmes, P.M., Rebelo, A.G., 1988. Effects of dry heat on seed germination in selected indigenous and alien legume species in South Africa. S. Afr. J. Bot. 54, 28 34

Keeley, J.E., 1987. Role of fire in seed germination of woody taxa in California Chaparral. Ecology 68, 434-443.

Krupek, A., Gaertner, M., Holmes, P.M., Esler, K.J., 2016. Assessment of post-burn removal methods for Acacia saligna in Cape Flats Sand Fynbos, with consideration of indigenous plant recovery. S. Afr. J. Bot. 105, 211-217.

Lamb, A.J., Klaussner, E., 1988. Response of the fynbos shrubs Protea repens and Erica plukenetii to low levels of nitrogen and phosphorus applications. S. Afr. J. Bot. 54, 558-564.

Levine, J.M., Vilà, M., D’Antonio, C.M., Dukes, J.S., Grigulis, K., Lavorel, S., 2003. Mechanisms underlying the impacts of exotic plant invasions. Proc. R. Soc. Lond. B Biol. Sci. 270, 775-781.

Le Maitre, D.C., Gaertner, M., Marchante, E., Ens, E.J., Holmes, P.M., Pauchard, A., O’Farrell, P.J., Rogers, A.M., Blanchard, R., Blignaut, J., Richardson, D.M., 2011. Impacts of invasive Australian acacias: implications for management and restoration. Divers. Distrib. 17, 1015-1029.

Le Maitre, D.C., Midgley, J.J., 1992. Plant reproductive ecology. In: Cowling, R.M. (Ed.), The Ecology of Fynbos: nutrients, Fire and Diversity. Oxford University Press, Cape Town, pp. 135-174.

Marais, K.E., Pratt, R.B., Jacobs, S.M., Jacobsen, A.L., Esler, K.J., 2014. Postfire regeneration of resprouting mountain fynbos shrubs: differentiating obligate resprouters and facultative seeders. Plant Ecol. 215, 195-208.

Marchante, H., Freitas, H., Hoffmann, J.H., 2011a. The potential role of seed banks in the recovery of dune ecosystems after removal of invasive plant species. Appl. Veg. Sci. $14,107-119$.

Marchante, H., Freitas, H., Hoffmann, J.H., 2011b. Post-clearing recovery of coastal dunes invaded by Acacia longifolia: is duration of invasion relevant for management success? J. Appl. Ecol. 48, 1295-1304.

Marchante, E., Kjøller, A., Struwe, S., Freitas, H., 2008. Short- and long-term impacts of Acacia longifolia invasion on the belowground processes of a Mediterranean coastal dune ecosystem. Appl. Soil Ecol. 40, 210-217.

Marchante, H., Marchante, E., Freitas, H., 2003. Invasion of the Portuguese dune ecosystems by the exotic species Acacia longifolia (Andrews) Willd .: effects at the community level. Plant Invasions: Ecological Threats and Management Solutions. The Netherlands, Backhuys, Leiden, pp. 75-85.

Maron, J.L., Jefferies, R.L., 1999. Bush lupine mortality, altered resource availability, and alternative vegetation states. Ecology 80, 443.

Moreno, J.M., Zuazua, E., Pérez, B., Luna, B., Velasco, A., Resco de Dios, V., 2011. Rainfall patterns after fire differentially affect the recruitment of three Mediterranean shrubs. Biogeosciences 8, 3721-3732.

Morgan, J., 1999. Have tubestock plantings successfully established populations of rare grassland species into reintroduction sites in western Victoria? Biol. Conserv. 89, 235-243.

Mostert, E., Gaertner, M., Holmes, P.M., Rebelo, A.G., Richardson, D.M., 2017. Impacts of invasive alien trees on threatened lowland vegetation types in the Cape Floristic Region, South Africa. S. Afr. J. Bot. 108, 209-222.

Moyes, A.B., Witter, M.S., Gamon, J.A., 2005. Restoration of native perennials in a California annual grassland after prescribed spring burning and solarization. Restor. Ecol. 13, 659-666.

Musil, C.F., 1993. Effect of invasive Australian acacias on the regeneration, growth and nutrient chemistry of South African lowland fynbos. J. Appl. Ecol. 30, 361-372.

Nsikani, M.M., Novoa, A., Van Wilgen, B., Keet, J., Gaertner, M., 2017. Acacia saligna's soil legacy effects persist up to 10 years after clearing: implications for ecological restoration. S. Afr. J. Bot. 42, 880-889.

Nsikani, M.M., van Wilgen, B., Gaertner, M., 2018. Barriers to ecosystem restoration presented by soil legacy effects of invasive alien $\mathrm{N}_{2}$-fixing woody species: implications for ecological restoration. Restor. Ecol. 26, 235-244.

Padilla, F.M., Pugnaire, F.I., 2006. The role of nurse plants in the restoration of degraded environments. Front. Ecol. Environ. 4, 196-202.

Pearson, D.E., Ortega, Y.K., Runyon, J.B., Butler, J.L., 2016. Secondary invasion: the bane of weed management. Biol. Conserv. 197, 8-17.

Pierce, S.M., Moll, E.J., 1994. Germination ecology of six shrubs in fire-prone cape fynbos. Vegetatio 110, 25-41.

Pretorius, M.R., Esler, K.J., Holmes, P.M., Prins, N., 2008. The effectiveness of active restoration following alien clearance in fynbos riparian zones and resilience of treatments to fire. S. Afr. J. Bot. 74, 517-525. 
Rebelo, A.G., Boucher, C., Helme, N., Mucina, L., Rutherford, M.C., 2006. The vegetation of South Africa. Mucina, L., Rutherford, M.C. (Eds.), 2006. The vegetation of South Africa. Fynbos Biome 52-219.

Richardson, D.M., Kluge, R.L., 2008. Seed banks of invasive Australian Acacia species in South Africa: role in invasiveness and options for management. Perspect. Plant Ecol. Evol. Syst. 10, 161-177.

Richardson, D.M., Rejmánek, M., 2011. Trees and shrubs as invasive alien species - a global review. Divers. Distrib. 17, 788-809.

Roche, S., Koch, J.M., Dixon, K.W., 1997. Smoke Enhanced Seed Germination for Mine Rehabilitation in the Southwest of Western Australia. Restor. Ecol. 5, 191-203.

Rokich, D.P., Dixon, K.W., 2007. Recent advances in restoration ecology, with a focus on the Banksia woodland and the smoke germination tool. Aust. J. Bot. 55, 375-389.

Rutherford, M.C., Powrie, L.W., Husted, L.B., Turner, R.C., 2011. Early post-fire plant succession in Peninsula Sandstone Fynbos: the first three years after disturbance. S. Afr. J. Bot. 77, 665-674.

Seabloom, E.W., Harpole, W.S., Reichman, O.J., Tilman, D., 2003. Invasion, competitive dominance, and resource use by exotic and native California grassland species. Proc. Natl. Acad. Sci. 100, 13384-13389.

Slingsby, P., Bond, W.J., 1983. Seed dispersal by ants in shrublands of the Cape Province and its evolutionary implications. S. Afr. J. Sci. 79, 231-233.

Standish, R.J., Cramer, V.A., Wild, S.L., Hobbs, R.J., 2007. Seed dispersal and recruitment limitation are barriers to native recolonization of old-fields in western Australia. J. Appl. Ecol. 44, 435-445.

Suding, K.N., Gross, K.L., Houseman, G.R., 2004. Alternative states and positive feedbacks in restoration ecology. Trends Ecol. Evol. 19, 46-53.

Tieu, A., Dixon, K.W., Meney, K.A., Sivasithamparam, K., 2001. The interaction of heat and smoke in the release of seed dormancy in seven species from Southwestern Western Australia. Ann. Bot. (Lond.) 88, 259-265.

Waller, P.A., Anderson, P.M.L., Holmes, P.M., Allsopp, N., 2016. Seedling recruitment responses to interventions in seed-based ecological restoration of Peninsula Shale Renosterveld, Cape Town. S. Afr. J. Bot. 103, 193-209.
Walther, G.R., Roques, A., Hulme, P.E., Sykes, M.T., Pyšek, P., Kühn, I., Zobel, M., Bacher, S., Botta-Dukat, Z., Bugmann, H., Czucz, B., 2009. Alien species in a warmer world: risks and opportunities. Trends Ecol. Evol. 24, 686-693.

Van Wilgen, B.W., Forsyth, G.G., 1992. Regeneration strategies in fynbos plants and their influence on the stability of community boundaries after fire. In: Van Wilgen, B.W., Richardson, D.M., Kruger, F.J., Van Hensbergen, J.J. (Eds.), Fire in South African Mountain Fynbos. Springer-Verlag, Berlin, pp. 54-80.

Van Wilgen, B.W., Le Maitre, D.C., Cowling, R.M., 1998. Ecosystem services, efficiency, sustainability and equity: south Africa's Working for Water Programme. Trends Ecol. Evol. 13, 378.

Van Wilgen, B.W., Viviers, M., 1985. The effect of season of fire on serotinous proteaceae in the Western Cape and the implications for fynbos management. S. Afr. For. J. $133,49-53$.

Wilkin, K.M., Holland, V.L., Keil, D., Schaffner, A., 2013. Mimicking fire for successful chaparral restoration. Madroño 60, 165-172.

Wilson, J.R., Gairifo, C., Gibson, M.R., Arianoutsou, M., Bakar, B.B., Baret, S. Celesti-Grapow, L., DiTomaso, J.M., Dufour-Dror, J.M., Kueffer, C., Kull, C.A., 2011. Risk assessment, eradication, and biological control: global efforts to limit Australian acacia invasions. Divers. Distrib. 17, 1030-1046.

Witkowski, E.T.F., 1991. Growth and competition between seedlings of Protea repens (L.) L. and the alien invasive, Acacia saligna (Labill.) Wendle. in relation to nutrient availability. Funct. Ecol. 101-110.

Wotsitsa, M., Mgese, S., 2012. Blaauwberg nature reserve land use history and current habitat condition assessment. Biodivers. Manag. Branch Cape Town.

Yelenik, S.G., Stock, W.D., Richardson, D.M., 2004. Ecosystem level impacts of invasive Acacia saligna in the South African fynbos. Restor. Ecol. 12, 44-51.

Yurkonis, K.A., Meiners, S.J., Wachholder, B.E., 2005. Invasion impacts diversity through altered community dynamics. J. Ecol. 93, 1053-1061.

Zink, T.A., Allen, M.F., 1998. The effects of organic amendments on the restoration of a disturbed coastal sage scrub habitat. Restor. Ecol. 6, 52-58. 